extract by mouth ( $1 \mathrm{lb}$. daily) resulted in no apparent improvement in three to four weeks. There was gradual improvement later on other treatments.

Case 8.--This patient, aged 22 , was seen in a first attack (subacute) of eight months' duration: stools two to four daily; slight anaemia only. Liver extract by mouth (1 lb. daily) led to no definite improvement in three weeks. She gradually got better later on other treatments.

\section{Diet and Drugs}

A good diet, adequately balanced, is of great importance. Many chronic colitis patients tend to take an excess of carbohydrate food, and care should be taken to avoid this. Patients should have small meals and never go long without food, and in particular they should avoid a heavy meal when fatigued. Iced food and drinks should be forbidden. Even during the acute attack, if appetite allows, a generous dist may be given, including milk for its salt and vitamin value, and first-class protein, as fish, eggs, chicken, and, later, mutton and beet. Small amounts of green-leaf vegetables (sieved), a cupful of orange or tomato juice, and marmite should be added. In convalescence fresh green-leaf salads, stewed fruit or pulped raw apple, pear, or banana may be ordered. The usual instructions to eschew food with coarse residue should be given.

Constipation should be treated with liquid paraffin and antispasmodics, as atropine or belladonna, especially whe: there is colicky pain. Mild aperients, as senna, are sometimes necessary, but should be omitted as far as possible. The dose of intramuscular liver was $2 \mathrm{c.cm}$. of concentrated preparation of tested potency in pernicious anaemia. In the massive iron therapy 90 grains of iron ammonium citrate were given daily. The yeast powder-a preparation of high potency in the vitamin B complex-was prescribed in doses of 3 drachms daily.

I am indebted to my colleagues at the Elizabeth Garrett Anderson Hospital for g:ving me access to their patients and records, and to the pathological staff of the hospital for their assistance.

\section{REFERENCES}

${ }^{1}$ Cramer, W.: Lancet, 1923, i, 1046

2 Goldblatt, H., and Benischek, M.: Journ. Exper. Med., 1927, xlvi, 699.

- McCarrison, R. Studies in Deficiency Discases, London 1921.

- Tilden, E. B., and Niller, E. G., jun.: Journ. of Nutrition, 1930, iii, 121

${ }^{5}$ Larimore, J. W.: Journ. Amer. Med. Assoc. 1928 xc. 841

6 Bargen, J. A., and Banks, B. M.: Arch. Int. Med., 1934, liii, 131

Castle, W. B., Heath, W. C., and Stracss, iI. B.: Amer. Journ. Med. Sci., 1931, clxxxii, 741 .

${ }^{8}$ Bennett, I., Hunter, D., and Vaughan, J. M.: Quart. Journ. Med, 1932, $x \mathrm{xy}, 603$

- Keefer, C. S., Yang, C. S., and Huang, K. K.: Arch. Int. Med.. 1931, xlvii, 436

The Queen Victoria Memorial Hospital at Welwyn, Herts, which the Duchess of York opened on July 24th, was founded in 1902. Until the present time it has been housed in the original bullding, to which additions were made from time to time. It is adjacent to a high road, which now carries a large amount of motor traffic. In consequence of a generous bequest made for the purpose of erecting an up-to-date cottage hospital in a quiet position, the committee was able to acquire an excellent site of about five acres and erect this new hospital.

The annual general meeting of the Medical Society of Individual Psychology was held at the Florence Restaurant, London, W., on July 12th. The chairman, Dr. J. C. Young, presided, and eighteen members dined together before proceeding to business. The present officers were re-elected. Dr. Neil Beattie and Dr. E. Taylor were elected to vacancies on the committee. The reports of the honorary secretary and honorary treasurer showed that the society is maintaining its position in membership and financial stability. An interesting programme is promised for next session.

\section{LATE TENDON SUTURE}

BY

ERIC I. LLOYD, F.R.C.S.

ORTHOPAEDIC SURGEON, ROYAL, NORTHERN HCSPITAL; SURCEON, HOSPITAL FOR SICK CHILDREN, GREAT ORMOND STREET

Although delay in the suture of a ruptured tendon diminishes the chance of success, there are occasions when excellent function follows a delayed operation.

\section{Rupture of the Tricsps Tendon}

The patient, a theatrical gymnast, sustained an accident while performing in a Paris music-hall. He was standing on his hands and supporting his partner's weight when he came upon a ridge in the carpet, which flung him sideways, so that he wrenched his left arm and tore his triceps tendon. The injury was apparently not diagnosed, and when seen three months later he had a gap of $1 / 2$ inch above the olecranon process, and was only able to extend the elbow by the feeble action of supinator longus and the forearm extensors. $\mathrm{He}$

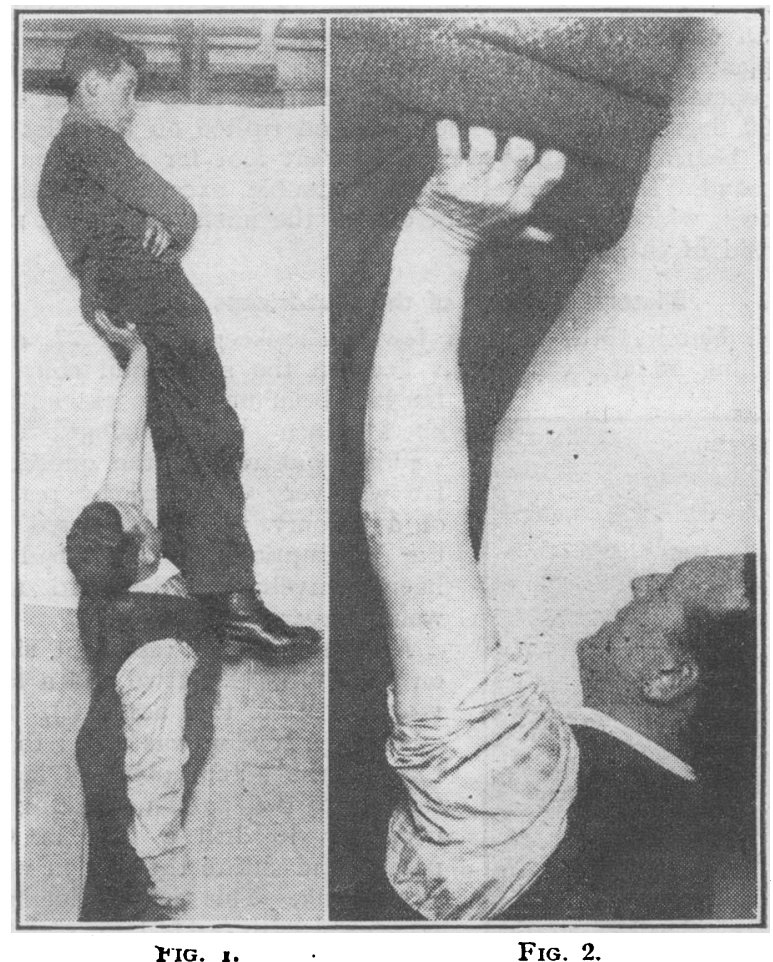

FIG. 1.-Cilse I. Rupture of left triceps tendon. Theatrical gymnast, alged 43, one year after reinforced suture performed three months after his accident.

FIG. 2.-Nearer view, showing situation of operation scar.

had done no work since the accident, and it was manifestly impossible for him to do so. $X$-ray examination showed a few flakes of the olecranon lying $1 / 2$ inch proximal to their normal insertion.

At operation, on May 24th, 1933 (three months after the accident), the tendon was found to be torn so close to the bone that clirect suture was impossible. A hole was drilled transversely through the olecranon, and a part of the tendon pulled down with strong catgut and threaded through this. Reinforcement was obtained by a length of half the width of peroneus longus tendon, which was passed through the bone and through two holes in the triceps tendon, and was then stitched both to tendon and to itself with catgut. The limb was left in extension for six weeks before exercises were attempted, but the patient then made such good progress that he was able to resume his occupation on October 1st, when he appeared at a music-hall at The Hague and considered his arm " normal " again. I have since seen his performance at a West-End music-hall, and he certainly did not spare his triceps.

The photographs were taken on March 24th, 1934, and show him supporting a 15-year-old boy a year after the accident. 


\section{Rupture of the Tendo Achillis}

A tea-planter, aged 38, was playing deck tennis on the homeward voyage when he felt a pain in his left leg, and found that he was quite unable to stand on tip-toe. He was so pleased to be home again that his condition was not diagnosed until four months after the accident, and valuable time had been lost.

At operation, on May 20th, 1931, it was found that a gap of $1 \frac{1}{2}$ inches in the tendo Achillis had been bridged by fibrous tissue. This was excised and the calf muscles mobilized, without, however, making direct apposition possible. The knee and anklo were flexed, but there was still a small gap to bridge. A length of $3 \frac{1}{2}$ inches of half the peroneus longus tendon was passed through the two ends of the tendo Achillis, and a part of the proximal end of the tendo Achillis was turned down and sutured to its distal part. No attempt was made to close the sheath, and there was considerable difficulty even to get the skin together. The limb was put in plasterof-Paris with the knee fully flexed and the ankle plantarflexed. The knee was extended in a week, and the foot brought to 110 degrees two weeks later, when the stitches were removed and the plaster changed.

Eight weeks from the operation the patient was walking in an ordinary shoe, with the heel raised half an inch, but no plaster or apparatus. When he was seen four months after the operation he was wearing an ordinary heel, his foot was at 90 degrees, 'and he could stand on tip-toe on the affected side, bearing his whole weight on that foot for a fraction of a second. He had experienced no trouble, except for a stitch abscess, which was no doubt due to the mistake of using silk instead of catgut.

\section{Bilateral Rupture of the Quadriceps Tendon}

On March 18th, 1932, a Jewish shopkeeper, aged 77, and weighing 16 st., caught his heel on the stairs and slipped.

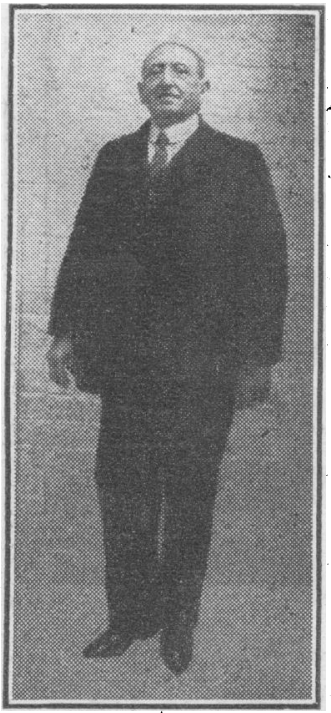

He had been unable to extend his knees since the accident, and walking was out of the question. He was very depressed by reason of a gloomy prognosis, based on the assumption that he had a haematomyelia of the cord and would never walk again.

At operation on the right side, on June 6th, 1932 (two and a half months after the accident), the quadriceps tendon was found to be torn at the actual point of insertion into the patella, making it necessary to drill a hole in the patella and suture the tendon with strong silk. This suture line was reinforced with fascia lata, and the capsule of the joint closed with catgut. Two weeks later the left side was operated upon, and a complete rupture disclosed and repaired.

A year later the patient was Fig. 3. - Case mir. seen at his little shop in Holborn ; Bilateral rupture of quadri- he could walk without sticks, and ceps tendon. Sixteen-stone had active extension of the knee patient, aged 79, nearly through 30 degrees. He did, howand reinforced suture. ever, generally use sticks for Operation two and a half walking, as he felt somewhat months after accident. insecure, no doubt partly owing to He can stand unaided, as his age and weight.
shown.

\section{Comment on Delayed and Reinforced Tendon Suture}

The successful results in these three cases are no argument for delay in suturing cut or ruptured tendons. The diagnosis of such an injury ought to be followed immediately by operation in any recent case. If, however, diagnosis or treatment has been delayed, there is still a good chance of getting a satisfactory result, even two or three months after an injury of the large extensor tendons. The story is an altogether different one for the smaller tendons, which are concerned with fine movement, such as those of the hand.

\section{Operative Technique}

The exact operation will vary in different cases, but the following points in technique seem reasonable.

1. The functional efficiency of a muscle demannds apposition of the torn ends of the tendon whenever possible and, failing that, the shorter the bridge the stronger will be the muscle.

2. Aids in securing apposition. Posture of adjacent joints and mobilization of muscle bellies help, but good honest pulling on the muscle generally helps more.

3. Suture material. Strong chromic catgut is the best, but it must be supported by splint or plaster-of-Paris for six weelss. Weight-bearing may be allowed during the latter half of the period if the sutured tendon is in the lower limb.

4. Supplementary sutures. Peroneal tendon and fascia lata will sometitnes turn doubt into security. They are always available in case of need.

5. The immediate post-operative position of a joint should relax the suture line, but if such is a malposition it must be gradually corrected in two or three weeks if the patient is an adult. In children this is not so essential.

6. It is much better to put the tendon through a hole in the bone than to stitch it to periosteum.

\section{A SECOND ATTACK OF ACUTE POLIOMYELITIS}

\author{
BY
}

THOMAS MOORE, M.B., B.S.

CLINICAL ASSISTANT TO THE ORTHOPAEDIC DEPARTMENT, ROYAL VICTORIA INFIRMIARY, NEWCASTLE-UPON-TYNE

The occurrence of a second attack of acute anterior poliomyelitis is rare.* In 1930 Still $^{1}$ reported one case, and was only able to collect eight definite cases from the literature. The diagnosis depends entirely on clinical evidence. In the case here reported this seems to be so complete as to leave no doubt as to the diagnosis.

\section{Case Record}

History.-On February 14th, 1934, W. L., aged 7 years was brought to the out-patient department of the-Royal Victoria Infirmary, Newcastle, because he was paralysed. His mother volunteered the following history. The child was healthy at birth; but at 10 months of age he had an attack of pneumonia. He was ill for fourteen days. After this the lower limbs seemed to " pine away," and he did not progress normally with learning to walk, as he had been doing previously. When the child was 3 years old he walked so badly - " his feet just seemed to flop about." - that his mother took him to see Dr. Nattrass at the Royal Victoria Infirmary (April 5th, 1930). He was given massage treatment and fitted with iron splints. He was able to walk remarkably well in these, used to go to school in them, and lived as a normal boy until eight weeks ago. He was then sent home from school because he was not well. The mother noticed that he wás " heavy" and feverish, and his nose was running. A doctor who was called in thought he was sickening for measles. In a day or two, however, he improved, and returned to school after a week's absence. A week later the child was taken ill again, and had to be put to bed. On the third day a rash appeared, which was diagnosed as measles. The child became very weak and helpless, and unable to feed himself. He complained of pains in his back and limbs, which were sore to the touch. After fourteen days an attempt was made to get the child up. It was then found he could neither stand nor sit.

* A short case record appeared in the Epitome of Current Medical Literature of June 9th, 1934, para. 474. 